\title{
EX - LIBRIS
}

El CRISOL, por Fernando Santiván.-2.* edición. Edit. Nascimento, Santiago, 1926.

Después de trece años de publicada la primera edición de .El Crisol., puede leerse como una obra inédita esta novela sobria. de lineas acentuadas y vigorosas. que tuvo la virtud de afirmar el nombre. tan nuevo para nuestras letras en 1913, de Fernando Santiván. Volvemos a gustar en ella los ambientes bien dibujados. los personajes de psicologia fijada con cerleza y el estilo simple y emotivo. Con más relieve y valor personal en la pintura de los jóvenes estudiantes de la Escuela de Artes y Oficios y en el diseño de esta especie de cárcel pedagógica. .El Crisol, nos muestra también interesantes aspectos de la existencia de una familia de la alta burguesia.

$\mathrm{Ha}$ preferido el autor, fiel a su antigua obra, no introducir en su nueva edición ninguna reforma, sea en lo sustancial o en lo exierior. Tal como conquistó sus primeros aplausos se presenta esta novela interesante y amena. Tal vez no la acojan el enlusiasmo y ardor del primer dia. pero oblendrá por lo menos una deferencia benévola y una simpatia cordial.

VIEnTos ContraRios, por Vicente Huidobro._Edit. Nascimento. Santiago, 1926.

En este último libro, el poeta Huidobro, acfualmente en Europa. se nos presenta como pensador y articulista. En las páginas de .Vientos contrarios, vemos un espectáculo interesan- 
tísimo: el movimiento agitado de las ideas de un ser joven de sumo talento. de temperamento exaltado y rico de vida, que choca y pugna contra todo lo establecido. Libro enconado, ardiente, contradictorio, encendido, chillón, agrio y mordaz, podría despertar la polémica si a su autor no se le hubiera distinguido en su patria, hace ya años, con el silencio.

En Europa seguramente. Vientos contrarios, se hará comentar y aplaudir: lo merece.

ENTRE LOS MUERTOS, por Elias Casfelnuovo.-Ediciones Atlas, Buenos Aires, 1926.

Elias Castelnuovo es un escritor de recia visión y de sólido talento. Su breve libro presente nos muestra unos cuantos relatos que logran dar cabalmente esa impresión. Llenos de perspectivas teatrales - el autor ha escrito piezas de teatro. - no es extraño ver en ellos violentos claroscuros y contrastes amargos y dilacerantes.

Si se nos pidiera un juicio de preferencia, vacilariamos entre «Agua!. sobria aguafuerte digna de un Gorki, .Animas benditas., sombrio relato a lo Poe, y Entre los muertos, caso de espanto y de locura. Todos ellos, al igual que .Reformatorios. poseen algún relieve propio que nos coge el espíritu y lo mantiene en suspenso y-¿por qué no decirlo?-sufriente.

El señor Castelñuovo no hace obra de folletin incoloro y por eso tal vez no goza de nombradia. pero su arte literario, más personal, más distintivo. logrará abrirle un camino.

Guía DEL CONTADOR, por Abel Guevara G.-Edit. Nascimento. Santiago, 1926.

Este libro está dirigido por su autor no al individuo enteramente ignaro en los recovecos de esta ciencia esotérica que se llama contabilidad. Es una obra para especialistas y persigue dar a los jefes de empresas y de casas de comercio lodos los principios que necesilan dominar para saber si las cuentas de 
sus negocios están bien llevadas y qué quieren decir para el futuro.

Los comerciantes $\mathrm{e}$ industriales son los llamados a decidir si este libro, bien impreso como todos los que salen de los talleres de Nascimento, cumple con el objetivo propuesto.

ORIENTAL, por Julio Silva.-Montevideo. 1926.

El señor Silva es un poeta de escasos recursos melódicos y de mucha riqueza de temas. La primera aserción se prueba leyendo algunos de sus versos. He aquí unos cuantos:

Era viejo mi abuelo.

Tenía los bolsillos llenos de bondad,

y en sus ojos claros el gran desconsuelo

de tener que irse a la Elernidad.

Habia vivido, habia guerreado, no habia muerto por casualidad: en el año veinte ya era soldado de la libertad.

Como se ve, el señor Silva no es un incondicional del precepto de Verlaine:

De la musique avant foute chose:

pero en cambio sabe hacer materia de arte cualquier tema: no sólo canta a sus antepasados y a las luchas en que ellos actuaron. sino que también entona una loa al football. representado por el famoso Petrone. Fácil y acaso sentida. la poesia del señor Silva pasa desgraciadamente sin dejar huellas.

POEMAS DE LA INMOVILIDAD Y CANCIONES AL SOL, por Luisa Luisi. Editorial Cervantes, Barcelona, 1926.

Luisa Luisi es uno de los grandes prestigios de América. Pedagoga, como Gabriela Mistral, como Maria de Maeztu. crítico de solidez y escuchado, escritora de estilo fuerte y cul- 
tura vastisima, es, por encima de todo esto, un alto y sereno poeta. Sus versos dan en lo magnifico. sin solemnidad declamatoria: van a lo hondo, sin descomponer el gesto: son todo espíritu y nobleza, todo humanidad a la vez.

poemas de la Inmovilidad y Canciones al Sol está reputándose en la critica, desde su aparición. como el mejor volumen de la poetisa. Y hay razón. Lo hemos comprobado.

LA ITALIA PRIMITIVA Y LOS COMIENZOS DEL IMPERIALISMO ROMANO, por León. Homo. La Evolución de la Humanidad. Editorial Cervantes. Barcelona, 1926.

En la Historia Universal no hay hecho más curioso que el desenvolvimiento de Roma, que desempeñó en la antigüedad un papel capital. tan distinto del de Atenas. Un conjunto de contingencias creó la ciudad que habia de llegar a ser el lmperio modelo de organización. En este volumen asistimos al nacimiento de Roma, a su portentoso crecimiento, a la extensión gradual de su actividad conquistadora y a la asimilación gradual de los pueblos itálicos y mediterráneos. El poderoso genio romano laboró para legar al mundo una vida social más perfecta. Su influencia ha sido, por lo menos, la más decisiva en la organización de las sociedades humanas posteriores.

La Italia primitiva y los comienzos del imperialismo romano deshace muchos errores y nos enseña verdaderamente a conocer a Roma, cuya historia habia sido falseada por los analistas romanos, en los que se han venido inspirando los creadores de la vulgata hislórica. El sabio profesor León Homo ha sabido estudiar el tema de su libro a través de recursos nuevos, a costa de largos y múltiples esfuerzos que destruyen la obra que habia venido forjando la leyenda. Su libro es precioso y luminoso. Es nuevo cuanto dice de los etruscos, este pueblo extraño que, como los hetitas y egeos. ha sido una de las más recientes revelaciones de la Historia. También constituye un especláculo sugestivo la formación de la civitas romana y luego del Imperio, que nos habia de dar las normas de la organiza- 
ción politica y jurídica, asi como la evocación de las guerras (Galia, Cartago, España, elc.) y de las alianzas, inspiradas igualmente en móviles económicos. $Y$ cuando este Imperio. el mayor de cuantos han existido. se extiende del bárbaro Occidente al mundo oriental, ya decadente, se prevé que Roma acabará por sentirse más atraida por las delicias del Oriente fastuoso y corrompido que por la vida sencilla del Occidente virgen.

El libro del profesor de la Universidad de Lyon está vertido al castellano por otro profesor universitario del ramo, en Santiago de Compostela: el doctor Luis Pericot.

Los CAMPEsinos (Otoño), por Ladislao Reymont. Los Principes de la Literafura. Editorial Cervantes. Barcelona, 1926.

La Editorial Cervantes comienza con esta-obra una nueva biblioteca: Los Principes de la Literatura. Buen comienzo. Los Campesinos, de Ladislao Reymont. Ileva entre su fama el dictado de ser, según muchos, la mejor novela de ambiente rural que se ha escrito en Europa. Somos enemigos hasta de repetir estos conceptos de prioridad tan rotunda: pero... en esle caso hemos querido hacer excepción. Se trata, desde luego, de una obra maestra.

El tomo que nos ha llegado es el primero. Oloño: pues Reymont, como el Marqués de Bradomin, ha seccionado el conjunto en cualro estaciones. Convencidos de la grandeza de genio que dió a Ladislao Reymont el Premio Nobel de Literatura en 1924, aguardamos interesados los volúmenes restantes. que, según se anuncia, constituirán los tomos II. III y IV de la biblioleca.

El Maravilloso Viaje de Nils Holgersson a travÉs DE SUECIA, por Selma Lagerlöf. Los Principes de la Literafura. Editorial Cervantes. Barcelona, 1926.

Es ésle realmente el Quijole de los niños suecos. Lo escri- 
bió Selma Lagerlöf con la intención de alzar un himno de las bellezas de su pais y a la vez-llevada por su amor a la infancia-deseosa de ofrecerle una lectura de amenidad, educación y encantamiento poético. El resultado fué una obra de sugestión tan poderosa, de lan envolvente poesía, que muy contados son los libros que tanto, tan profunda y tan dulcemente nos han impresionado. Fué ésle el libro que-primer caso en Europa-abrió las puertas académicas a una mujer.

La traducción es de primer orden. Un triunfo más de Vicente Clavel, que se ha hecho asesorar en esla ocasión, sin duda a causa del idioma del original, por Carlos A. Talavera, poliglota repulado.

La obra constituye el tomo $\mathrm{V}$ de la biblioteca sos Principes de la Literalura.. Si la Editorial Cervantes, que ha lanzado esta nueva biblioleca, sigue con tino tan extraordinario en su labor. continuará el éxito iniciado con ¿Los Campesinos».

\section{Las Mejores poesías de los Mejores Poetas. Jacinto} Verdaguer. Editorial Cervantes. Barcelona, 1926.

El fomito LII de esla ya célebre colección reúne un haz de poemas de Jacinto Verdaguer, el poeta de los Pirineos, como por antonomasia se le llamó.

La fama del ilustre hijo de Vich ha resonado en todos los espiritus cultos, para que con esta ocasión necesitemos repetir sus fundamentos. El nombre de Verdaguer es la bandera que sus compatriotas han clavado en su tienda poética, para que flamee frente al Dante italiano, al Milton de Inglaterra, al Goethe alemán, al Hugo de los franceses, al Klopstock de Rusia. Pero debemos, sí, decir que esta selección está bien, muy bien hecha, y que las traducciones, no en balde a cargo de poetas elegidos, merecen franco elogio. 